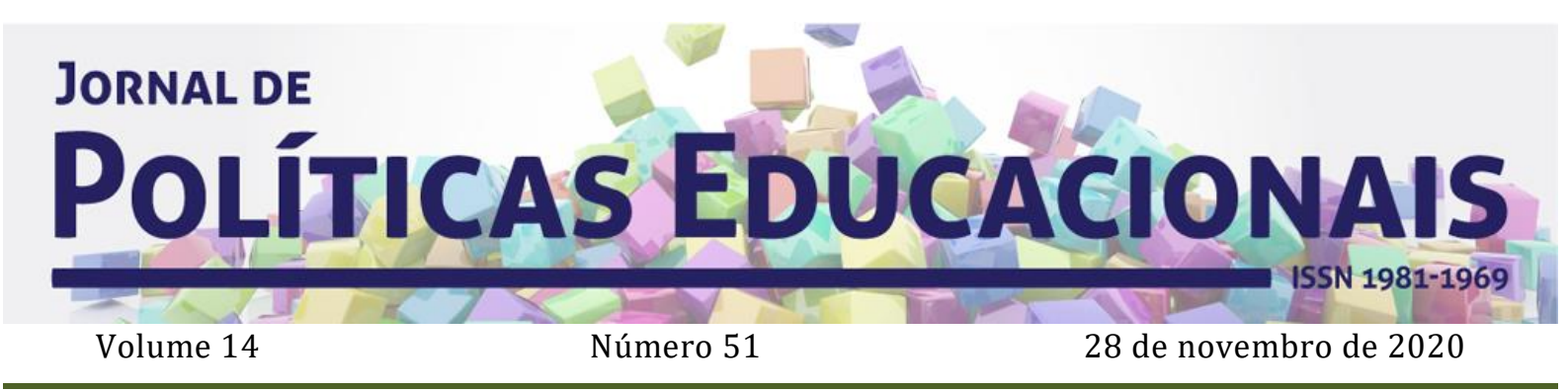

\title{
A tessitura do Plano Nacional do Livro e Leitura (2006-2016) no Brasil sob a influência de organismos internacionais
}

\author{
The tessiture of the National Book and Reading Plan \\ (2006-2016) in Brazil under the influence of international organisms
}

\section{La tessitura del Plan Nacional del Libro y Lectura (2006-2016) en Brasil bajo la influencia de organismos internacionales}

\author{
Lidiane Tavares do Nascimento Gomes ${ }^{1}$ \\ Ilma de Andrade Barleta ${ }^{2}$
}

Citação: GOMES, L. T. do N; BARLETA, I. de A. A tessitura do Plano Nacional do Livro e Leitura (2006-2016) no Brasil sob a influência de organismos internacionais. Jornal de Políticas Educacionais. V. 14, n. 51. Novembro de 2020.

http://10.5380/jpe.v14i074222

\begin{abstract}
Resumo
0 artigo teve como objetivo analisar as influências de organismos internacionais na constituição da política de leitura no Brasil que originaram o Plano Nacional do Livro e Leitura (2006-2016) no contexto do Estado capitalista. Tratou-se de uma pesquisa bibliográfica e documental, embasada, principalmente, nos estudos de Evangelista (2008; 2009), Croso e Magalhães (2016), Peroni (2018), Avelar (2019), dentre outros, analisados à luz da Análise de Discurso Crítica (ADC). As principais fontes analisadas são documentos oficiais nacionais e de organismos internacionais, como o CERLALC e a OEI. A investigação apontou reflexões relevantes sobre a forma que a Política Nacional de Leitura, atualmente em curso, está organicamente alinhada à lógica global, aos auspícios dos organismos internacionais, especialmente, quando esses documentos orientam para a inserção
\end{abstract}

\footnotetext{
${ }^{1}$ Graduada em Letras. Professora da rede pública de ensino do Estado do Amapá. Mestranda em Educação, na Linha de Políticas Educacionais, pelo Programa de Pós-Graduação em EducaçãoPPGED/UNIFAP. Macapá, AM. Brasil. Orcid: https://orcid.org/0000-0001-8010-8334. E-mail: lidiane.tn@gmail.com 2 Doutora em Educação. Professora da Universidade Federal do Amapá-UNIFAP. Integra o corpo docente permanente do Programa de Pós-Graduação em Educação-PPGED/UNIFAP. Macapá, AM. Brasil. Orcid: https://orcid.org/0000-0002-4345-7700 E-mail: ilmabarleta@gmail.com
} 
de representantes da cadeia produtiva do livro na formulação da política de leitura e, como consequência, abrem espaço para a atuação do mercado, por meio do preceito democrático de acesso.

Palavras-chave: política de leitura, organismos internacionais, privatização, PNLL, política educacional.

\begin{abstract}
The article aimed to analyze the influences of international organisms in the constitution of the reading policy in Brazil that originated the National Book and Reading Plan (2006-2016) in the context of the Capitalist State. It was a bibliographical and documentary research, based, mainly, on the studies of Evangelista (2008; 2009), Croso and Magalhães (2016), Peroni (2018), Avelar (2019), among others, analyzed in the light of the Analysis of Discourse Critical (ADC). The main sources analyzed are official documents from national and international organisms, such as CERLALC and OEI. The investigation pointed relevant reflections on the way that the National Reading Policy, currently underway, is organically aligned with the global logic, with the auspices of international organisms, especially, when these documents guide to the insertion of representatives from book's production chain in the formulation of the reading policy and, as consequence, they open space for the market acting, through the democratic precept of access.
\end{abstract}

Keywords: reading policy, international organisms, privatization, PNLL, educational policy.

\title{
Resumen
}

El artículo tuvo como objetivo analizar las influencias de organismos internacionales en la constitución de la política de lectura en Brasil que originaron el Plano Nacional do livro e leitura (2006 - 2016) (Plan Nacional del Libro y Lectura) en el contexto del Estado capitalista. Se trató de una investigación bibliográfica y documental, basada, principalmente, en los estudios de Evangelista (2008; 2009), Croso y Magalhães (2016), Peroni (2018), Avelar (2019), entre otros, analizados a la luz de la Análise de Discurso Crítica (ADC) (Análisis del Discurso Crítica). Las principales fuentes analizadas son documentos oficiales nacionales y de organismos internacionales, como el CERLALC y la OEI. La investigación apuntó reflexiones relevantes sobre la forma que la Política Nacional de Lectura, actualmente en curso, está orgánicamente alineada a la lógica global, a los auspicios de los organismos internacionales, especialmente, cuando esos documentos orientan para la inserción de representantes de la cadena productiva del libro en la formulación de la política de lectura y, como consecuencia, abren espacio para la actuación del mercado, por medio del precepto democrático del acceso.

Palabras clave: política de lectura, organismos internacionales, privatización, PNLL, política educacional.

\section{Introdução}

A política educacional brasileira vem sendo definida a partir de diretrizes consensuadas internacionalmente. Isso se dá em função do papel estratégico que a escolarização ocupa para o desenvolvimento sócio-econômico-produtivo de país. Com efeito, diferentes campos da educação organizados pela política e legislação educacional, poderão trazer as intencionalidades advindas dos organismos multilaterais do capitalismo que disputam a função social da escola.

Partimos do pressuposto de que a leitura relaciona-se não somente com as dimensões políticas, epistemológicas e ontológicas, mas também com os processos educativos que se dão no âmbito das escolas e que reverberam diretrizes não advindas desse contexto. Assim, questionamos: como a Política de leitura brasileira expressa no PNLL se constitui a partir de diretrizes de organismos internacionais? 
Esta indagação levou à definição do objetivo geral desta pesquisa: analisar as influências de organismos internacionais na constituição da política de leitura brasileira no contexto do Estado capitalista. Este estudo integra a dissertação de mestrado intitulada "Linhas e entrelinhas da democratização no Plano Nacional do Livro e LeituraPNLL" desenvolvida na linha de Políticas Educacionais do Programa de Pós-Graduação em Educação da Universidade Federal do Amapá-PPGED/UNIFAP.

A fim de compreendermos as influências dos organismos internacionais nos discursos presentes no PNLL (2006-2016) investigamos documentos derivados destas instituições, uma vez que os documentos de Política Educacional expressam não somente diretrizes para a educação, mas trazem em seu bojo interesses políticos e produzem intervenções sociais (EVANGELISTA, 2009). Tendo em vista o caráter analítico, baseado em documentos da política de leitura, adotamos como procedimento a Análise de Discurso Crítica (ADC), proposta por Norman Fairclough (2012), uma abordagem teórico-metodológica para o estudo da linguagem voltado ao tratamento dos recursos linguísticos utilizados por determinados atores sociais e suas relações com as práticas da vida social.

Para dar conta disso, o corpus selecionado está representado por documentos oficiais nacionais relacionados ao PNLL e de organismos internacionais concernentes à temática livro e leitura: Portaria Interministerial no 1442/2006 (que institui o Plano Nacional do Livro e Leitura- PNLL); Decreto no 7.559/2011 (que dispõe sobre o Plano Nacional do Livro e Leitura - PNLL e dá outras providências); Caderno do PNLL; Guia de Elaboração e Implantação dos Planos Estadual e Municipal do Livro e Leitura; La política nacional del libro: guía para el trabajo de campo (UNESCO); Agenda de políticas públicas de lectura (OEI/CERLALC); Guía para el diseño de planes nacionales de lectura (OEI/CERLALC); e Nueva Agenda por el libro e lectura: recomendaciones para políticas públicas en Iberoamérica (CERLALC).

Para exposição do estudo realizado estruturamos o texto em duas seções: inicialmente, apresentamos os lineamentos traçados por Organismos Internacionais na Política de Leitura Brasileira; em seguida, analisamos a privatização entretecida por organismos internacionais na política de leitura brasileira por meio dos documentos. Nas considerações finais do artigo sinalizamos que o PNLL, atualmente em curso, está organicamente alinhado a uma agenda global que orienta, por meio dos organismos internacionais, a inserção de representantes da cadeia produtiva do livro na formulação 
da política de leitura e, como consequência, abre espaço para a atuação do mercado, por meio do preceito democrático de acesso.

\section{Lineamentos traçados por Organismos Internacionais na Política de Leitura}

\section{Brasileira}

O Plano Nacional do Livro e Leitura-PNLL, para o decênio 2006-2016, foi instituído pela Portaria Interministerial no 1442 de 10 de agosto de 2006 e, segundo o próprio documento, é produto do compromisso do governo federal de construir políticas públicas e culturais com base em um amplo debate com a sociedade. Tal ato firmou-se quando o Brasil subscreveu a Declaração de Santa Cruz de La Sierra, durante a XIII Conferência Ibero-americana de Chefes de Estado e de Governo dos vinte e um países signatários da Organização dos Estados Ibero-americanos para a Educação, a Ciência e a Cultura (OEI).

Notamos, assim, que o Brasil articula-se à OEI e referida rede de governança, a partir de seus referenciais internacionais, os quais incidem diretamente no delineamento da Política Nacional de Leitura, isto é, a política pensada por essa agência internacional, influencia o setor governamental brasileiro e traz diretrizes significativas para o país, inclusive, quanto ao aspecto financeiro/econômico, uma vez que o Vivaleitura foi concebido na forma de prêmio.

Diante disso, ler as entrelinhas da política de leitura requer buscar compreendêla como resultado de imperativos globais materializados por organizações multilaterais, entre as quais podemos citar: O Banco Mundial (BM), a OEI, a Organização das Nações Unidas para a Educação, a Ciência e a Cultura (UNESCO) e, no caso da política aqui analisada, mais especificamente, o Centro Regional para o Fomento do Livro na América Latina e o Caribe (CERLALC).

Para Leher (1999) a participação decisiva dos organismos internacionais na educação brasileira é algo que já não provoca tantas controvérsias, uma vez que as contradições da crise estrutural do capitalismo já não permitem atuações discretas. Ao contrário, as recomendações oriundas dos agentes internacionais são entendidas como caminhos a serem seguidos pela política educacional dos países da periferia do capitalismo.

Prova disso, é a atuação do Banco Mundial que, ao examinar o desempenho do sistema educacional, apresenta três funções principais: i) o desenvolvimento das 
habilidades da força de trabalho a fim de gerar crescimento econômico; ii) a contribuição para a redução da pobreza e da desigualdade através de oportunidades educacionais para todos; iii) a transformação de gastos educacionais em resultados educacionais (BM, 2010).

Relacionando essas funções à leitura, podemos inseri-la da seguinte forma: i) leitura como necessidade para o trabalho; (ii) leitura como equidade social; iii) leitura como resultado de investimentos. Ao considerarmos os pontos levantados pelo BM, trazemos para análise os gastos com a compra de livros, por exemplo, através do Programa Nacional do Livro e Material Didático (PNLD), tendo em vista os resultados por meio de avaliações externas, especialmente, o Programa Internacional de Avaliação de Estudantes (PISA). Um dos objetivos do PNLL traz à tona essa questão: "contribuir para a formação de leitores autônomos, buscando, de maneira continuada, substantivo aumento do índice nacional de leitura e do nível qualitativo das leituras realizadas, considerando os diferentes públicos" (BRASIL, 2014, p. 25).

Esses imperativos ditados pelo BM, com reflexos no PNLL, trazem em seu bojo uma concepção profundamente impregnada da Teoria do Capital Humano, porque vincula a educação ao desenvolvimento econômico, como enfatiza Frigotto (2006), em que um determinado volume de conhecimentos, habilidades a atitudes adquiridas passam a ser considerados como potencializadores da capacidade de trabalho e de produção.

Desta forma, para compreendermos o acesso ao livro por meio das políticas de distribuição, é imperativo nos questionarmos sobre os interesses por essa causa, o seu conteúdo e a sua metodologia; conhecer como a política é pensada e estruturada e, para isso, é essencial avaliar também quem são os fazedores desta política para além do Estado. Estamos falando dos novos atores e novas formas de governança que surgiram na política educacional, principalmente, a partir de 1990.

Essas complexas redes de governança, de acordo com Avelar (2019, p. 74) são as "novas vozes provenientes do setor privado, que não são eleitas, nem supervisionadas pela população [as quais] têm tido participação significativa na determinação de políticas educacionais". A mencionada autora enfatiza que essas novas dinâmicas da política, em forma de redes, dão lugar tanto a sujeitos quanto a espaços de "relacionamento público-privado", assim, governo, filantropia e mercado influenciam a formulação e a execução da política (AVELAR, 2019). 
Neste sentido, sujeitos individuais e coletivos estão cada vez mais presentes e organizados em redes (do local ao global) e, desta forma, atuam com diferentes graus de influência de acordo com os diferentes espaços que ocupam: setor financeiro, organismos internacionais, setor governamental (PERONI, 2018). Em se tratando da política de leitura brasileira, a rede aparece por meio do chamamento de atores da cadeia do livro e leitura para a formulação do PNLL, conferindo o caráter de participação.

Contudo, Croso e Magalhães (2016) ressaltam que essa forma de participação (direta ou indireta) de representantes do setor privado no debate e na definição da agenda pública educativa é, na verdade, a privatização da política, a qual Ball e Youdell (2007 apud CROSO e MAGALHÃES, 2016) chamam de "privatização acobertada", tanto no âmbito internacional como no nacional.

Para Ball e Youdell (2007 apud CROSO; MAGALHÃES, 2016) existem dois tipos de "privatização acobertada": a privatização endógena (endoprivatização) que introduz a lógica do mercado na educação por meio da individualização, da competição e do ranqueamento; e a privatização exógena (exoprivatização) que insere atores privados nos espaços públicos de educação e vende insumos advindos da iniciativa privada.

O nascedouro do Plano Nacional do Livro e Leitura (o Prêmio Vivaleitura), nada mais é do que a própria endoprivatização, quando insere a lógica meritocrática, individualista, competitiva, em direta conexão com os ideais do mercado. Por outro lado, a exoprivatização aparece na inclusão de representantes da cadeia produtiva do livro: editores, livreiros, distribuidores, gráficas, fabricantes de papel, escritores, administradores, gestores e outros profissionais do mercado editorial (MARQUES NETO, 2010), interessados no debate e na definição da referida política para "o livro" no Brasil.

A privatização da educação não apenas fragiliza os sistemas públicos de educação, mas também coloca em xeque o caráter público da educação, bem como preceitos democráticos, na medida em que disputa seus sentidos e propósitos e transfere ao setor privado elementos essenciais da prática educativa (CROSO; MAGALHÃES, 2016, p. 31).

Essa abertura para privatização é parte do projeto neoliberal que, a partir do diagnóstico do capital de crise do Estado, leva-o a redefinir o seu papel, abrindo espaço para a atuação do mercado na busca do parâmetro de qualidade. Aí está a raiz do avanço da privatização do público, de acordo com Peroni (2018), e é por isso que as políticas 
educacionais no contexto das forças hegemônicas acabam reduzindo a educação a um insumo econômico, o que traz consideráveis implicações para o projeto democrático no país e no mundo.

De acordo com Avelar (2019) as fronteiras entre o público e o privado, refletem também as redes globais que são entrelaçadas para operar pretensões mercadológicas, uma vez que essa é a centralidade dos interesses do capital. Há, portanto, arranjos por parte da classe empresarial, que atua hegemonicamente e, assim, influencia (com maior ou menor grau) na definição e nos encaminhamentos da política: "os empresários se apropriam de bandeiras de luta dos movimentos sociais e educacionais e as ressignificam, construindo consenso em torno da ideia de um pacto de "educação para todos", nos moldes da gestão empresarial” (BERNADI, UCZAK e ROSSI, 2018, p. 122).

Essas redes que estabelecem as fronteiras entre os países e instituições privadas também foram construídas quando do planejamento para a definição da Política Nacional do Livro. Neste contexto, alguns eventos objetivaram o alinhamento de discursos e projetos, como a Reunião para a formulação de uma agenda de políticas públicas de leitura, realizada no período de 13 a 15 de setembro de 2004, em Cartagena das Índias, na Colômbia, a qual contou com a participação de 18 (dezoito) especialistas da leitura e do livro de 10 (dez) países. Assim,

\begin{abstract}
se elaboró, en conjunto, un documento guía, con el propósito de recomendar objetivos, acciones y medios para trabajar por el fomento de la lectura desde una perspectiva integral que involucra la voluntad estatal y la articulación de los diversos sectores interesados en la materia. (CERLALC/OEI, 2004, p. 7).
\end{abstract}

Essa perspectiva integral atende os diferentes setores da cadeia do livro e da leitura (autores, editoras, fabricantes de papel, gráficas, livreiros, dentre outros) e, com isso, as empresas que passam a entretecer nas políticas suas ideias e seus objetivos: o mercado de livros.

Como vemos, está em disputa um emaranhado de redes políticas constituídas por instituições internacionais (especialmente da América Latina e Caribe), grupos privados visando a interferir no planejamento e na definição do Plano de leitura brasileiro. Peroni (2018, p. 102) chama a atenção para os objetivos de classes por trás das redes, tendo em vista que "o Estado, assim como o capital, é entendido como relação ou processo em um movimento de sujeitos em correlação de forças de classes sociais e projetos societários 
distintos". Logo, as redes carregam objetivos de uma classe dominante, na busca da permanência de um projeto de nação, cujo alicerce é ditado pelo capital.

Desta forma, o setor privado enraíza-se no seio dos serviços públicos educacionais, a começar pela política, como estamos apresentando nesta investigação, isto é, um processo de mercantilização da educação (a leitura e a mercadoria: o livro), principalmente quando analisamos a Política Nacional do Livro (com ênfase no objeto livro) ao invés de Política Nacional de Leitura (com ênfase nas práticas leitoras), por exemplo. A PNL está estruturada do seguinte modo: i) Capítulo I: da Política Nacional do Livro; ii) Capítulo II: do Livro; iii) Capítulo III: da Editoração, Distribuição e Comercialização do Livro); iv) da Difusão do Livro; v) Disposições gerais (BRASIL, 2003).

Os grifos objetivam destacar o vínculo entre o livro e o setor privado. Isso porque o Ilímita (Plano Ibero-Americano da Leitura) de iniciativa do Centro Regional para o Fomento do Livro na América Latina (CERLALC), o qual alinhavou a Agenda para a Leitura dos países membros (inclusive o Brasil), traz dentre os seus objetivos (CERLALC, 2011, p, 135): i) melhorar o acesso ao livro e outros materiais de leitura; ii) vincular o setor privado ao fomento da leitura; iii) fortalecer o mundo do livro para a criação, a produção e a comercialização do mesmo.

A nosso ver esses objetivos convergem para uma tríade que ilustra o que estamos analisando: o acesso, o setor privado, a comercialização. Isto é, para promover o acesso à leitura, o público abre espaço para atuação do privado, com vistas ao mercado livreiro. Peroni (2018) enfatiza a problemática da privatização na América Latina e no mundo todo. Para ela, a presença da lógica mercantil no campo educacional, fomentando "verdadeiras indústrias e negócios" objetivando a extração de lucros.

Partilhando dessas ideias, Catini (2019) frisa que a mimese da produtividade empresarial acaba reduzindo o trabalho educativo ao produto, num movimento fetichista bastante conhecido: "em conjunto com a transferência de responsabilidade dos direitos sociais para o setor privado, criou as bases para que a relação mercantil e produtiva deixe de ser um simulacro ou a subsunção do capital, se dê completamente" (CATINI, 2019, p. 35).

A transferência de responsabilidades e de recursos públicos ao setor privado provoca a redefinição do papel do Estado e, como consequência, há a quebra da garantia do direito à leitura, portanto, ao processo de democratização. Ao mesmo tempo em que ocorrem algumas conquistas sociais para a democratização da educação, em um 
processo de correlação de forças, verifica-se a organização de setores vinculados ao mercado, influenciando as políticas educativas das mais diferentes formas (PERONI, 2018, p. 99-100).

A bandeira de luta chamada democratização, também foi apropriada como um direito materializado no PNLL, enquanto resultado de reclames populares (democratização do acesso à leitura). Contraditoriamente, essa democratização está voltada à participação, à coletivização de decisões, pois o Estado reconfigura o público quando vincula a ele o privado (e sua lógica mercantil), privatizando, assim, o acesso ao livro, o que traz sérias consequências para a democratização da educação (e da leitura).

\section{A privatização entretecida por organismos internacionais na política de leitura brasileira}

A política para a leitura e o livro no Brasil, especialmente expressa no PNLL, está inserida num processo amplo de organização da vida social, política e econômica que pode ser denominado de internacionalização, pautado em uma agenda globalmente estruturada para a educação, a qual se reproduz em documentos de políticas educacionais nacionais como programas, projetos de lei, entre outros. Por esse motivo, é importante evidenciar, na forma de documentos, algumas destas orientações globalizadas, conforme veremos a seguir.

La política nacional del libro: guía para el trabajo de campo (UNESCO- 1995/2005)

O documento foi concebido por Álvaro Garzón López ${ }^{3}$ como um guia para os responsáveis (públicos e privados) da produção e distribuição editorial, com a finalidade de desenvolver programas de promoção do livro e da leitura, ou seja, aborda uma política cultural de desenvolvimento do livro.

Neste sentido, de acordo com a UNESCO,

Promover el libro implica así luchar también contra la pobreza en el sentido de que se libra una batalla estratégica de interés general que no sólo concierne a los especialistas, sino a todos los que trabajan en la construcción de un mundo más abierto y más solidario. Además, el libro ocupa un lugar importante en el quehacer de la UNESCO, que le ha consagrado, desde su creación, numerosas iniciativas de reflexión, de apoyo a las políticas de los países en la materia, de formación y de consolidación professional (UNESCO, 2005, p. 7-8).

\footnotetext{
${ }^{3}$ Artista plástico e benfeitor cultural. Foi secretário-geral da Comissão Colombiana da UNESCO e secretário-geral da CERLALC, ambos em Bogotá. Foi consultor do Banco Interamericano de Desenvolvimento (BID) e da UNESCO.
} 
O interesse da UNESCO pela promoção do acesso ao livro, cujo discurso é o combate à pobreza, está fundado no desenvolvimento da economia por meio do conhecimento e, assim, traz a leitura como um importante instrumento para isso. Projetos neoliberais, entre os quais está a Política Nacional do Livro, suprem os pobres com o mínimo (neste caso, a distribuição gratuita de livros) com vistas a desviar as tensões para não comprometerem a perspectiva econômica da ação.

Esse caráter econômico pode ser visto no "guia", documento em que são expostos os objetivos de uma Política Nacional do Livro, no sentido de garantir que todos os níveis da sociedade possam acessar livros mais facilmente. Para isso, "es necesario trabajar con la compleja estructura cultural, industrial y comercial que media entre el autor y el lector" (UNESCO, 2005, p. 17).

O caminho do acesso ao livro (como bem cultural) até o leitor envolve uma cadeia industrial e comercial, como bem aponta o documento. Nele, também são apresentados os subsetores envolvidos: i) o autor; ii) o editor; iii) a gráfica; iv) o distribuidor, o livreiro; v) o leitor, as bibliotecas, seguidos do diagnóstico, da definição da política e dos mecanismos para o desenvolvimento do livro para cada um desses subsetores. Por fim, são expostos alguns encaminhamentos para a Lei do Livro, o Acordo entre o setor público e privado e a Estratégia da Política do Livro (guia para o trabalho de campo), com aspectos específicos para o livro didático.

Em outras palavras a agenda para a leitura que surge a partir desses encaminhamentos internacionais, traz em seu ínterim não só o livro como um insumo cultural, mas também industrial e comercial, portanto, econômico. Em nossa leitura, as recomendações da UNESCO são acatadas pelo Estado brasileiro quando este aprova a Lei no 10.753/2003, que institui a Política Nacional do Livro, a chamada "Lei do Livro" e apresenta a ideologia de desenvolvimento econômico, alinhavada internacionalmente.

\section{Agenda de políticas públicas de lectura (OEI-CERLALC- 2004)}

0 documento foi elaborado por vários autores, após a Reunião para a Formulação de uma Agenda de Políticas Públicas de Leitura, realizada na cidade de Cartagena das Índias, em setembro de 2004, convocada pela Cerlalc e pela OEI no âmbito do Plano Ibero-Americano de Leitura - o ILÍMITA. Trouxe em seu texto prioridades, recomendações, ações e meios para desenvolver a promoção da leitura numa perspectiva integral que envolve o Estado e os diversos setores interessados no assunto (OEI-CERLALC, 2004). Foi elaborado de forma conjunta, por especialistas do sistema 
livro e leitura provenientes de dez países participantes, entre os quais está o Brasil, nas figuras de Jeanete Beauchamp ${ }^{4}$ e de Galeno Amorim ${ }^{5}$.

O Plano Ibero-Americano de Leitura é uma iniciativa que trabalha para a articulação entre governos, setor privado e sociedade civil, a fim de estabelecer, na região, ações imediatas e de longo prazo em favor da leitura. Trata-se de uma definição estratégica de política pública, da qual faz parte a Cúpula dos Chefes de Estado, no sentido da construção social que enquadra o papel das instituições, ações governamentais e de acordos necessários para a formulação de planos de leitura, leis de livros, entre outros.

Una de las principales líneas de acción de ILíMITA es convertir el fomento de la lectura en un tema de política pública, por lo cual, la Organización de Estados Iberoamericanos para la Educación, la Ciencia y la Cultura, OEI, y el Centro Regional para el Fomento del Libro en América Latina y el Caribe, Cerlalc -instituciones encargadas del diseño y la ejecución del Plan en los veintiún países de Iberoamérica. (OEI- CERLALC, 2004, p. 7).

Notamos que a "Agenda" apresentada aos responsáveis pelos Planos Nacionais de Leitura, traz conclusões, recomendações, pressupostos e prioridades: considerar a leitura como política pública é reconhecer que ela não tem um valor neutro, pois está intimamente relacionada a "procesos sociales que las convierten en una poderosa herramienta para la democratización y la participación social" (OEI-CERLALC, 2004).

Traz, ainda, 10 (dez) estratégias para a implementação dessas prioridades e seus respectivos responsáveis, beneficiários, objetivos, ações recomendadas e meios para execução, entre as quais estão: i) tratar as políticas de leitura como parte integral das políticas de Estado, articuladas aos diferentes níveis de governo e setores que trabalham a promoção da leitura; ii) garantir o acesso à cultura escrita a toda a população, como responsabilidade de toda empresa e tarefa prioritária do Estado; iii) estabelecer mecanismos de participação da sociedade civil organizada para a construção de uma política de leitura pública.

Notamos que há uma conciliação das diretrizes regionais de organismos internacionais para a formulação do Plano Nacional do Livro e Leitura, uma vez que essa agenda é elemento basilar tanto para o Brasil quanto como para os demais países que compõem a América Latina e Caribe, área de atuação do CERLALC. A leitura como ferramenta para a democratização e a participação social, também embasa o documento

\footnotetext{
${ }^{4}$ Diretora de Políticas de Educação Infantil e Ensino Fundamental- MEC.

${ }^{5}$ Diretor do Plano Nacional do Leitura-MinC.
} 
brasileiro, já na sua concepção: “o caráter descentralizado e democrático do Plano deve ser demarcado como premissa dessa política do Estado desde o início do processo" (BRASIL, 2009, p. 13). Isto é, as recomendações internacionais, incidem sobre as recomendações nacionais e estas sobre os estados e municípios, no contexto da elaboração dos planos.

\section{Guía para el diseño de planes nacionales de lectura (OEI-CERLALC, 2007)}

Trata-se de um documento produzido por Beatriz Helena Isaza Mejía ${ }^{6}$ e Carlos Sánchez Lozano ${ }^{7}$ no contexto do Plano Ibero-Americano de Leitura - ILÍMITA. Os conteúdos e alvos foram apresentados no II Encontro Ibero-Americano de responsáveis de políticas públicas de Leitura, realizado em Cartagena das Índias, na Colômbia, em agosto de 2005. Assim, representantes dos Ministérios da Educação e Cultura da América Latina e Caribe (entre os quais estava Galeno Amorim), diretores de fundações de fomento à leitura, gerentes de associações privadas e diretores de bibliotecas trouxeram ideias que geraram a formulação deste material.

O guia "surge en respuesta a la solicitud que varios países hicieron al Cerlalc, en el sentido de elaborar bases que les sirvieran como apoyo en el proceso de formulación de programas de estas características" (OEI-CERLALC, 2007, p. 9). Traz, inicialmente, seus antecedentes, propósitos, público-alvo; seguidos de uma estrutura geral para o desenho de um plano nacional de leitura.

De acordo com o documento, o desenho necessário para a formulação de um plano nacional de leitura está traçado em três marcos: i) o conceitual (ideias ou concepções que definem e orientam as ações necessárias para alcançar o produto final); ii) o situacional (o cenário do plano como referência e como suporte para a proposta a ser formulada); iii) o operacional (aspectos práticos voltados à fase de formulação como condição para sua implementação).

Em relação ao marco conceitual está, além da democratização, a concepção de leitura. Inclusive, ela é apresentada no Plano brasileiro a partir de dois eixos norteadores "práticas sociais" e "construção de sentidos", respectivamente:

\footnotetext{
${ }^{6}$ Psicóloga e instrutora de mediadores de leitura e escrita (professores, bibliotecários, promotores de leitura, pais, entre outros.); É autora de textos escolares; desenha e coordena propostas de formação virtual e presencial para autores, editores, livreiros, professores e mediadores da leitura.

${ }^{7}$ Linguista, autor e editor de livros educacionais, editor de livros de literatura infantil e trabalha em programas de formação de professores. É consultor do CERLALC-UNESCO, onde coordenou atividades voltadas a projetos de treinamento para atores na área de livros.
} 
leitura e a escrita são percebidas aqui como práticas essencialmente sociais e culturais, expressão da multiplicidade de visões de mundo, esforço de interpretação que se reporta a amplos contextos; assim, a leitura e a escrita são duas faces diferentes, mas inseparáveis, de um mesmo fenômeno. (BRASIL, 2014, p. 15, grifos nossos).

A concepção de leitura focalizada pelo Plano é aquela que ultrapassa o código da escrita alfabética e a mera capacidade de decifrar caracteres, percebendo-a como um processo complexo de compreensão e produção de sentidos, sujeito a variáveis diversas, de ordens social, psicológica, fisiológica, linguística, entre outras [...] A leitura configura um ato criativo de construção de sentidos, realizado pelos leitores a partir de um texto criado por outro(s) sujeito(s) (BRASIL, 2014, p. 16-17, grifos nossos).

Contudo, por mais que as linhas do Plano tratem a leitura como construção de sentidos e prática social, notamos que os direcionamentos dados num contexto global, e seus diferentes graus de influência, representam para além dos anseios da classe (atores do livro e leitura), os interesses do setor governamental, dos organismos internacionais, inclusive, do setor econômico.

E, ao buscarmos pesquisar o PNLL, tomamos a leitura como essa construção de sentidos que se dá numa determinada prática social. Assim, o leitor agente é capaz de transitar por diferentes contextos, relacionando habilidades de leitura com necessidades, valores e práticas sociais (SOARES, 2004).

Nueva Agenda por el libro e lectura: recomendaciones para políticas públicas em Iberoamérica (CERLALC, 2013)

É um documento produzido no contexto do Centro Regional para o Fomento do Livro na América Latina e Caribe (CERLALC) por Roberto Igarza8, cujo texto é constituinte das deliberações do Comitê Intergovernamental em reunião ocorrida em julho de 2013 na cidade de Bogotá.

Além dos interlocutores naturais (como os ministérios de cultura e educação dos países membros), o CERLALC também se relaciona com outras entidades: subnacionais, associações, organizações profissionais, instituições privadas, organizações da sociedade civil que atuam em qualquer das áreas relativas a sua missão:

Nuestro propósito, en los últimos años, ha sido el de fortalecer ese papel: transformar el CERLALC em um centro de pensamiento, que acompañe a los países miembros en la construcción de políticas públicas alrededor del

\footnotetext{
${ }^{8}$ Engenheiro e doutor em Comunicação Social. Desenvolveu estudos pioneiros sobre a incidência de TIC no consumo cultural com interseção entre Cultura, Comunicação e Tecnologias. É consultor de organizações e governos internacionais em políticas públicas e programas de educação e cultura.
} 
libro y la lectura, de manera informada, com diagnóstico, reflexión y convicción. (CERLALC, 2013, p. 11).

A Nova Agenda para o Livro e a Leitura é composta por 229 (duzentos e vinte e nove itens) para os quais aponta 214 (duzentas e quatorze) recomendações, ambos reunidos em 7 (sete) indicadores, a saber: i) contexto global e regional: sua caracterização; ii) entorno tecnológico; iii) leitura e escrita como ferramentas para a democracia; iv) os mediadores; a cadeia de valor; v) os papéis do Estado. Contudo, concentraremos nossas discussões nos itens iii e v.

"A agenda do futuro" surge como orientação para tomada de decisões estratégicas. 0 documento contextualiza que as populações mais vulneráveis socialmente, para as quais a leitura continua condicionada pelo acesso ao suporte impresso, às mediações e ao papel do Estado; e um novo segmento populacional (vívido, hiperconectado), ligado ao sistema de mídia cultural, para o qual o acesso à internet é tido como democratização em termos de educação e cultura, o que traz novos desafios para as políticas públicas.

Para isso, enfatiza, entre outras questões, os papéis desempenhados pelo Estado, enquanto promotor de leitura, prescritor de conteúdos culturais, produtor de conteúdos, facilitador de infraestruturas sócio-tecnológicas e agente regulador e fiscal, bem como a influência desses papéis na configuração do cenário atual da área livro e a leitura na América Latina e Caribe, especialmente no Brasil.

No item "Leitura e escrita como ferramenta para a democracia" a leitura está principalmente relacionada à aquisição de livros e à inclusão digital, isto é, democratização da leitura como materialização de direitos. Por outro lado, ambas estão conectadas ao crescimento econômico e regional, alinhadas, portanto, ao fator financeiro.

Quanto ao item "Os papéis do Estado", as recomendações traduzem o projeto econômico por trás do plano a ser definido, como o alinhamento dos indicadores de leitura do setor em termos econômicos, uma vez que pontua as compras públicas, com foco na inovação visando ao acesso (inclusão digital, bibliodiversidade, por exemplo); contemplando, assim, as diferentes fontes e os diversos suportes de informação. Para isso, traz a participação representativa dos atores da cadeia do livro, bem como a importância da cooperação multilateralista. 
Neste sentido, Evangelista (2013, p. 37) alerta que "sob a forma de Organizações Multilaterais, está em causa a manutenção da perspectiva capitalista, da reprodução das relações capitalistas de produção, da consolidação do neoliberalismo, à revelia da crise em andamento". E reafirma a necessidade de uma educação para além do capital.

Como vimos, os pontos apresentados nos documentos no curso desta exposição estão organicamente alinhados à lógica global, pois, notamos claramente que as políticas educacionais brasileiras estão sob os auspícios dos organismos internacionais, particularmente os da América Latina e Caribe, tendo em vista que os documentos originários desses organismos multilaterais são referenciais às políticas educacionais no Brasil para a área do livro e da leitura.

O Plano Brasileiro, conforme encaminhamentos do Plano Ibero-Americano, abre espaço para as "empresas privadas", as "instituições privadas", ou "instituições do terceiro setor" como estratégia de financiamento, de apoio cultural, mas também (e principalmente!) para atores da cadeia produtiva do livro (editores, livreiros, distribuidores, gráficas, fabricantes de papel, escritores), o que reflete, certamente, interesses privados.

Essa Política de Estado se traduz em amplos programas do governo, com coordenações interministeriais devidamente articuladas com estados, municípios, empresas e instituições do terceiro setor, para alcançar sinergia, objetividade e resultados de fôlego quanto às metas que venham a ser estabelecidas. (BRASIL, 2014, p. 2, grifos nossos).

Essa articulação entre o Estado brasileiro e as instituições privadas e do terceiro setor, está voltada às estratégias burguesas, isto é, "as ações estatais têm como elementos decisivos a definição de um marco regulatório mais flexível e uma estrutura menos burocrática, ambas voltadas a dois objetivos: impulsionar a economia capitalista e repolitizar a política" (LIMA; MARTINS, 2005, p. 58). De acordo com os autores, esse primeiro objetivo está voltado à defesa da parceria público-privada, com vistas à eficiência e a agilidade do mercado; mas também à cobertura de ações que envolvem empresas e ONGs na provisão de bens e, assim, o estabelecimento de novos parâmetros econômicos. Como está posto no Plano.

A partir dos delineamentos traçados por organismos internacionais, especialmente, da América Latina e Caribe, como o CERLALC, podemos constatar uma lógica privativista e mercadológica que se perfaz de modo fetichizante. 0 que vimos nos documentos analisados foi que o compromisso do PNLL não é com as práticas leitoras (acesso à leitura), e sim, com o livro (acesso ao livro), isto é, uma mercadoria como 
qualquer outra, mas que é ocultada, intencionalmente, a fim de mascarar as desigualdades sociais próprias do capitalismo.

\section{Considerações finais}

A política de leitura no Brasil, expressa no PNLL (2006-2016), relaciona-se às necessidades sociais e políticas de conservação, ajustada à concepção de mundo hegemônico. Por isso, acreditamos que as ações que orientam fundamentalmente na conformação de uma estrutura educacional como veículo de efetivação das exigências do modelo social vigente, devem ser consideradas a partir de uma reflexão crítica, que revele as contradições ocultadas nessas políticas, como buscamos fazer neste percurso investigativo.

Neste sentido, vimos que organizações multilaterais, entre as quais está a UNESCO, a OEI e o CERLALC, atuam com diferentes graus de influência de acordo com os diferentes espaços que ocupam. No caso da Política de Leitura Brasileira, esses organismos internacionais ofereceram orientações significativas para 0 seu delineamento, especialmente, para a formulação do Plano Nacional do Livro e LeituraPNLL e, como consequência, trouxeram novas formas de regulação. Entre elas, está a abertura para o setor privado, o qual passa a atuar na política com pretensões mercadológicas, uma vez que a classe empresarial se apropria da bandeira de luta dos movimentos sociais em favor da leitura, e traz para os documentos (portanto, para a política) o discurso da democratização do acesso ao livro e à leitura em seus diferentes formatos e temas.

Em suma, pesquisar sobre políticas educacionais é investigar suas agendas, uma vez que elas refletem formas em que a sociedade neoliberal tem se organizado no sentido de manter a hegemonia capitalista, cujo objetivo é a permanência deste projeto de sociedade. Logo, o PNLL é, na verdade, um Plano Internacional, como visto na tessitura deste artigo.

\section{Referências}

AVELAR, Marina. 0 público, o privado e a despolitização nas políticas educacionais. In: CÁSSIO, Fernando (org.). Educação contra a barbárie: por escolas democráticas e pela liberdade de ensinar. São Paulo: Boitempo, 2019. 
BANCO MUNDIAL. Atingindo uma educação de nível mundial no Brasil: próximos passos. Sumário executivo, $2010 . \quad$ Disponível em: http://portal.mec.gov.br/index.php?option=com docman\&view=download\&alias=7289 -banco-mundial-pdf\&Itemid=30192. Acesso em: 28 jan. 2020.

BERNADI, Liane Maria; UCZAK, Lucia Hugo; ROSSI, Alexandre José. Relações do movimento empresarial na política educacional brasileira: a naturalização da associação público-privada. In: PERONI, Vera Maria Vidal; LIMA, Paula Valim de.; KADER, Carolina Rosa (orgs.). Redefinições das fronteiras entre o público e o privado: implicações para a democratização da educação. São Leopoldo: Oikos, 2018.

BRASIL. Institui o Plano Nacional do Livro e Leitura. Portaria Interministerial no 1442 de 10 de agosto de 2006. Disponível em: http://www.cultura.gov.br/pnll. Acesso em 17 set. 2017.

BRASIL. Dispõe sobre o Plano Nacional do Livro e Leitura (PNLL) e dá outras providências Decreto $\mathrm{n}^{\mathbf{0}} 7.559$ de $1^{\circ}$ - de setembro de 2011.. In: BRASIL . Legislação sobre livro e leitura. 2 ed. Brasília: Câmara dos Deputados, 2013.

BRASIL. Caderno do PNLL: edição atualizada e revisada. Brasília: MEC/MinC, 2014. Disponível em: http://www.cultura.gov.br/pnll. Acesso em 17 set. 2017.

BRASIL. Guia para elaboração e implantação dos Planos estadual e municipal do livro e leitura. Brasília: 2009. Disponível em : http://www.cultura.gov.br/pnll. Acesso em 17 set. 2017.

BRASIL. Lei no 10.753 de 30 de outubro de 2003. Institui a Política Estadual do Livro. In: BRASIL. Legislação sobre livro e leitura. 2 ed. Brasília: Câmara dos Deputados, 2013.

CATINI, Carolina. Educação e empreendedorismo da barbárie. In: CÁSSIO, Fernando (org.). Educação contra a barbárie: por escolas democráticas e pela liberdade de ensinar. São Paulo: Boitempo, 2019.

CERLALC. Nueva agenda por el libro y la lectura: recomendaciones para políticas públicas en Iberoamérica. Colômbia: UNESCO, 2013. Disponível em:

https://cerlalc.org/pt-br/publicaciones/nueva-agenda-por-el-libro-y-la-lecturarecomendaciones-para-politicas-publicas-en-iberoamerica/. Acesso em: 12 set. 2019.

CROSO, Camilla; MAGALHÃES, Giovanna Modé. Privatização da educação na América Latina e no Caribe: tendências e riscos para os sistemas públicos de ensino. Revista Educação e Sociedade. Campinas, v. 37, n. 134, p. 17-33, jan./mar. 2016. Disponível em: https://www.scielo.br/scielo.php?pid=S0101-

3302016000100017\&script=sci abstract\&tlng=pt. Acesso em: 04 out. 2017.

EVANGELISTA, Olinda. Apontamentos para o trabalho com documentos na política educacional. I Colóquio A pesquisa em trabalho, educação e políticas educacionais. Belém: UFPA, 2009.

EVANGELISTA. Olinda. Qualidade da educação pública: Estado e Organismos Multilateriais. In: LIBÂNEO, José Carlos; SUANNO, Marilza Vanessa Rosa; LIMONTA, 
Sandra Valéria (orgs.). Qualidade na escola pública: políticas educacionais, didática e formação de professores. Goiânia: Ceped, 2013.

FAIRCLOUGH, Norman. Análise Crítica do Discurso como método em pesquisa social científica. Tradução de Iran Ferreira de Melo. Linha d'água: estudos linguísticos e/ou novas linguagens no ensino. São Paulo: USP, n. 25, v. 2, p. 307-329, 2012.

FRIGOTTO, G. A produtividade da escola improdutiva: um (re)exame das relações entre educação e estrutura econômico-social capitalista. 8 ed. São Paulo: Cortez, 2006.

LEHER, Roberto. Um Novo Senhor da educação? A política educacional do Banco Mundial para a periferia do capitalismo. Outubro Revista. ed. 3, art. 3, p. 19-30, 2015. Disponível em: http://outubrorevista.com.br/wpcontent/uploads/2015/02/Revista-Outubro-Edic\%CC\%A7a\%CC\%83o-3-Artigo-03.pdf. Acesso em: 01 fev. 2020.

LIMA, Kátia Regina de Souza; MARTINS, André Silva. Pressupostos, princípios e estratégias. In: NEVES, Lúcia Maria Wanderley (org.). A nova pedagogia da hegemonia: estratégias para educar o consenso. São Paulo: Xamã, 2005.

MARQUES NETO, José Castilho. PNLL: textos e história (2006-2010). São Paulo: Cultura Acadêmica, 2010.

OEI-CERLALC. Agenda de Políticas Públicas de Lectura. Colômbia: OEI, 2004.

Disponível em:https://cerlalc.org/pt-br/publicaciones/agenda-de-politicas-publicasde-lectura/. Acesso em: 25 jan. 2020.

OEI-CERLALC. Guía para el diseño de planes nacionales de lectura. Colômbia: OEI, 2007. Disponível em: https://cerlalc.org/pt-br/publicaciones/guia-para-el-diseno-deplanes-nacionales-de-lectura/. 25 jan. 2020.

PERONI, Vera Maria Vidal. Implicações da relação público-privada para a democratização da educação. In: PERONI, Vera Maria Vidal; LIMA, Paula Valim de.; KADER, Carolina Rosa (orgs.). Redefinições das fronteiras entre o público e o privado: implicações para a democratização da educação. São Leopoldo: Oikos, 2018.

UNESCO. La Política Nacional del Libro: guia para el trabajo del campo. França: UNESCO, 2005. Disponível em: https://cerlalc.org/pt-br/publicaciones/la-politicanacional-del-libro-guia-para-el-trabajo-de-campo/. Acesso: 25 jan. 2020.

SOARES, Magda. Letramento: um tema em três gêneros. 2 ed. Belo Horizonte: Autêntica, 2004. 


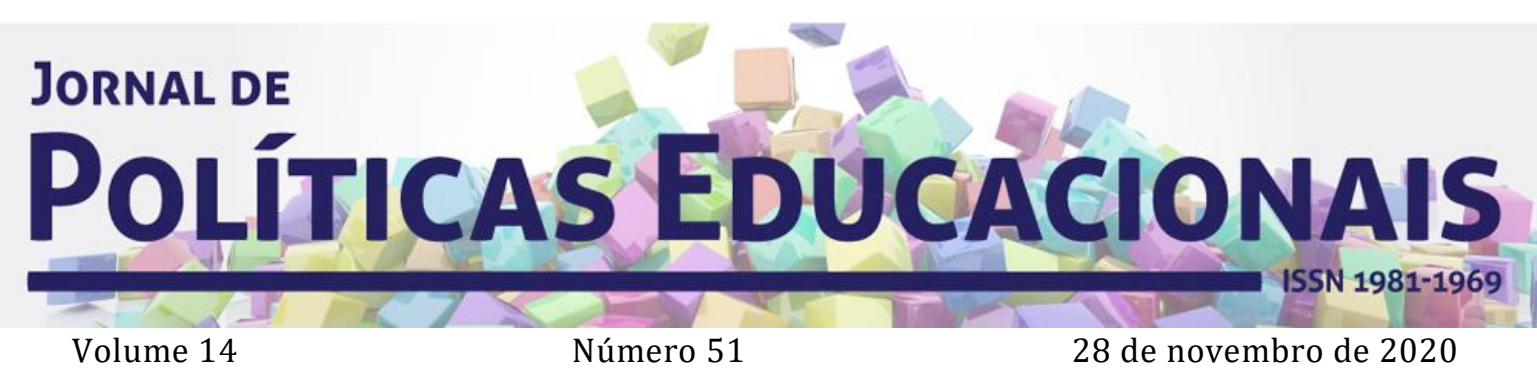

(C)

SORERIGHIS RESERNED O Copyright é retido pelo/a autor/a (ou primeiro co-autor) que outorga o direito da primeira publicação ao Jornal de Políticas Educacionais. Mais informação da licença de CreativeCommons encontram-se em http://creativecommons.org/licenses/by-nc-nd/2.5. Qualquer outro uso deve ser aprovado em conjunto pelo/s autor/es e pelo periódico.

JoRnal De Políticas Educacionais é uma publicação do Núcleo de Políticas Educacionais do Setor de Educação da Universidade Federal do Paraná - NuPE/UFPR, em consórcio com a Linha de Pesquisa em Políticas Educacionais do Programa de Pós-Graduação em Educação - PPGE/UFPR, que aceita colaboração, reservando-se o direito de publicar ou não o material espontaneamente enviado à redação. As colaborações devem ser enviadas ao NuPE/UFPR, conforme orientações contidas nas páginas do periódico na internet: http://revistas.ufpr.br/ipe.

\author{
Indexação: \\ BBE - Biblioteca Brasileira de Educação (MEC/INEP) \\ Clase (Base de Datos Bibliográfica de Revistas de Ciencias Sociales y Humanidades) \\ Diadorim - Diretório de Política de Acesso Aberto das Revistas Científicas Brasileiras (IBICT) \\ Google Scholar \\ Index Copernicus \\ Portal de Periódicos (CAPES) \\ SER - Sistema Eletrônico de Revistas da Universidade Federal do Paraná (SER/UFPR) \\ Sumários de Revistas Brasileiras (FUNPEC-RP) \\ DRJI - Directory of Research Journals Indexing
}

(Periódico integralmente disponível apenas em via eletrônica)

Jornal de Políticas Educacionais / Núcleo de Políticas Educacionais da Universidade Federal do Paraná -

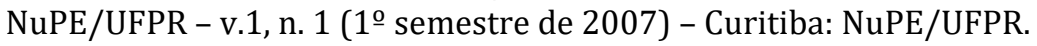

Volume 14, número 51 - Novembro de 2020

ISSN 1981-1969

1. Educação - Periódicos. 2. Política Educacional - Periódicos. I. NuPE/UFPR

Comitê Editorial:

Elisângela Scaff (UFPR)

Daniela de Oliveira Pires (UFPR)

Conselho Editorial:

Andréa Barbosa Gouveia (UFPR - Brasil), Cesar Tello (Universidad Nacional Tres Febrero, Argentina), Fernanda Saforcada (Universidad de Buenos Aires - UBA - Argentina), Gladys Beatriz Barreyro (USP Brasil), Gustavo Enrique Fischman, (Arizona State University - USA), Jefferson Mainardes (UEPG - Brasil), João Ferreira de Oliveira (UFG - Brasil), Juca Gil (UFRGS - Brasil), Luiz Souza Júnior (UFPB - Brasil), Ney 
GOMES, L. T. do N; BARLETA, I. de A. A tessitura do Plano Nacional do Livro e Leitura (2006-2016) no Brasil sob a influência de organismos internacionais

Cristina Monteiro de Oliveira (UFPA - Brasil), Nicolás Bentancur, (Universidad de la República de Uruguay), Robert Verhine (UFBA - Brasil), Rosana Cruz (UFPI - Brasil), Rubens Barbosa Camargo (USP Brasil), Sebastián Donoso Díaz (Universidad de Talca - Chile), TheresaAdrião (UNICAMP - Brasil), Vera Peroni (UFRGS - Brasil).

Créditos e Agradecimentos:

Revisão de Língua Portuguesa, Abstract e Resumen: PROGRAMA DE APOIO ÀS PUBLICAÇÕES CIENTÍFICAS PERIÓDICAS DA UFPR

Arte e diagramação: TIAGO TAVARES (tiagotav@gmail.com)

Jornal de Políticas Educacionais

Universidade Federal do Paraná

Setor de Educação

Núcleo de Políticas Educacionais - NuPE/UFPR

Avenida Sete de Setembro, 2645

$2^{\circ}$ andar, Sala 213

80.230-010 - Curitiba - PR - Brasil

Tel.: 41-3535-6264

jpe@ufpr.br

http://revistas.ufpr.br/jpe 